Rev. Bras. Saúde Prod. Anim., Salvador, v.16, n.2, p.337-349 abr./jun.., 2015 http://www.rbspa.ufba.br

\title{
Características da carcaça de cordeiros submetidos à dietas com inclusão de levedura seca de cana-de-açúcar ${ }^{1}$
}

\author{
Carcass characteristics of lambs fed diets with inclusion of sugar cane dry yeast
}

ARAÚJO FILHO, José Teodorico de ${ }^{2}$; AMORIM, Philipe Lima de ${ }^{2} *$ MONTEIRO,
Ironaldo Alvares ${ }^{2}$; FREGADOLLI, Fábio Luiz ${ }^{2}$; RIBEIRO, José Denison Marinho

${ }^{1}$ Pesquisa financiada pela FAPEAL.
${ }^{2}$ Universidade Federal de Alagoas, Centro de Ciências Agrárias, Rio Largo, Alagoas, Brasil.
*Endereço para correspondência: philipe.amorim@ceca.ufal.br

\section{RESUMO}

Objetivou-se estimar os efeitos da substituição do farelo de soja por levedura seca de cana-deaçúcar sobre as características da carcaça e não carcaça de cordeiros terminados em confinamento. Foram avaliados quatro tratamentos $(0,0 ; 33,0 ; 66,0$ e $100,0 \%)$ que consistiam de níveis de inclusão de levedura seca em substituição ao farelo de soja, num delineamento experimental de blocos inteiramente casualizados, com nove repetições. A substituição do farelo de soja por levedura seca diminuiu linearmente os não constituintes da carcaça, consumo de matéria seca, ganho de peso diário, peso corporal ao abate, conformação, grau de acabamento das carcaças, rendimento de carcaça e cortes cárneos. A inclusão de levedura não interferiu nas características cor do Longíssimus dorsi e gordura renal, enquanto para área de olho de lombo, gordura pélvica renal e escore corporal, ao passo que se incluía levedura seca houve diminuição dessas variáveis. A margem bruta por cordeiro diminuiu à medida que se incluiu a levedura seca nas dietas. A substituição do farelo de soja por levedura seca de cana-deaçúcar afeta negativamente as características da carcaça e não carcaça dos cordeiros.

Palavras-chave: agroindústria, Saccharomyces cerevisiae, Santa Inês, subprodutos, substituição

\section{SUMMARY}

The objective was estimate the effects of replacing soybean meal by dry yeast sugarcane on carcass characteristics and non-carcass of lambs finished in feedlot. We evaluated four treatments $(0.0, \quad 33.0, \quad 66.0$ and $100.0 \%)$ consisting of sugar cane dry yeast inclusion levels to replace soybean meal in an experimental randomized complete block design with nine repetitions. The replacement of soybean meal by sugar cane dry yeast decreased linearly constituents non-carcass, dry matter intake, daily weight gain, body weight at slaughter, conformation, degree of completion of the carcasses, carcass yield and meat cuts. The inclusion of sugar cane dry yeast did not affect the color of the longissimus dorsi and kidney fat, while for rib eye area, renal pelvic fat and body condition, whereas if included sugar cane dry yeast there was a decrease of these variables. Gross margin decreased by lamb as it included the sugar cane dry yeast in the diet. The replacement of soybean meal by sugar cane dry yeast sugarcane negatively affects carcass and non-carcasscharacteristics of lambs.

Keywords: agribusiness, byproducts, replacement, Saccharomyces cerevisiae, Santa Ines 


\section{INTRODUÇÃO}

Uma das opções para amenizar os efeitos climáticos na produção de ovinos no nordeste brasileiro, sobre a qualidade e oferta de carne ao mercado consumidor, seria a exploração em sistemas intensivos, sobretudo, confinamentos. No entanto, a adoção desse tipo de sistema encontra obstáculos em relação ao custo da dieta, um dos aspectos mais importantes na produção de carne, além da necessidade de infraestrutura específica.

A busca por alimentos alternativos com objetivo de reduzir custos da dieta sem, no entanto, reduzir a qualidade ofertada aos animais, se faz uma alternativa interessante a ovinocultores. A utilização de subprodutos da agroindústria pode ser uma saída para redução desses custos, pois, em muitos casos, sua maior oferta ocorre quando os demais ingredientes da dieta (milho e soja, por exemplo) estão com preço elevado.

Dentre os subprodutos da agroindústria, o oriundo da sucroalcooleira, merece atenção, devido ao tamanho da área cultivada com cana-de-açúcar no Brasil, além da sua crescente expansão. Durante o processo industrial do etanol, é gerada grande quantidade de resíduos, dentre eles, as leveduras (Saccharomy cescervisiae). Nas indústrias de álcool, devido à intensidade de crescimento destes microorganismos, ocorre excesso de produção de levedura, que depois de desidratada, pode ser usada para diversos fins, como por exemplo, na alimentação animal (GRANGEIRO et al., 2001).

Embora se apresente como alternativa a substituição do farelo de soja por seu elevado teor proteico, sua inclusão deve ser limitada, pois, a mesma apresenta menores valores de nutrientes digestíveis totais (NDT), além de frequentes variações em sua composição química, quando comparada ao primeiro. Dentre as características de produção animal que sofrem interferência da dieta ofertada, o rendimento de carcaça e dos cortes cárneos são diretamente influenciadas. A estimativa do rendimento da carcaça e cortes comerciais, por ocasião do abate, é de suma importância para complementar avaliação do desempenho do animal. Ademais, o rendimento de carcaça e cortes cárneos tem efeito direto sobre o retorno econômico à propriedade rural $\mathrm{e}$ potencial retorno com a comercialização das carnes pelo frigorífico.

Objetivou-se com este experimento avaliar características de carcaça e não constituintes da carcaça de cordeiros submetidos a dietas com inclusão de levedura seca de cana-de-açúcar.

\section{MATERIAL E MÉTODOS}

O experimento foi conduzido no setor de ovinocultura do Centro de Ciências Agrárias da Universidade Federal de Alagoas localizado no município de Rio Largo - AL (latitude de $9^{\circ} 27^{\prime} \mathrm{S}$, longitude de $35^{\circ} 27^{\prime} \mathrm{W}$ e uma altitude média de $127 \mathrm{~m}$ ), no período de Julho a Setembro de 2011. O clima da região é do tipo As segundo classificação climática descrita por Köppen, com período seco nos meses de Setembro até Maio.

Foram avaliados quatro tratamentos, que consistiam em níveis de substituição do farelo de soja por levedura seca de cana-de-açúcar $(0,0$; 33,$0 ; 66,0$ e $100 \%$ ), num delineamento de blocos inteiramente casualizados, com nove repetições.

Foram utilizados 36 cordeiros, nãocastrados, da raça Santa Inês, com idade aproximada de 120 dias e peso corporal 
Rev. Bras. Saúde Prod. Anim., Salvador, v.16, n.2, p.337-349 abr./jun.., 2015 http://www.rbspa.ufba.br ISSN 15199940

médio de $21,46 \mathrm{~kg}( \pm 3,4)$. O período experimental teve duração de 79 dias, com período de adaptação de 14 dias, onde os cordeiros receberam as dietas ad libitum. Após esse período, os animais foram pesados, identificados com brincos numerados, vacinados contra clostridiose e vermifugados, sendo a vermifugação repetida 15 dias após a primeira.

Os cordeiros permaneceram em regime de confinamento, em baias individuais $(1,0 \mathrm{~m} \times 1,2 \mathrm{~m})$ contendo água, alimento e cama de maravalha de madeira, que eram limpas diariamente. Quando necessário, para controle de eimerioses, foi administrado nos animais tratamento com sulfaquinoxalina sódica $25 \mathrm{~g}$ por quatro dias.

Os animais foram pesados a cada 14 dias e receberam dieta na proporção de $5 \%$ do peso corporal de forma a permitir $10 \%$ de sobras. A dieta foi fornecida duas vezes ao dia, às 8:00 e 15:00 horas. A dieta foi constituída por $50 \%$ de volumoso, constituído por feno de capim Tifton-85 (Cynodon spp.), e $50 \%$ de concentrado à base de fubá, farelo de soja, levedura seca de cana-deaçúcar corrigida com ureia (dependendo do tratamento), calcário, sal mineral e comum. As quatro dietas experimentais foram formuladas para ganhos diários de 250g/dia (NRC, 1985) (Tabela 1).

Tabela 1. Ingredientes e composição percentual e química das rações experimentais

\begin{tabular}{lcccc}
\hline \multirow{2}{*}{ Ingredientes* } & \multicolumn{4}{c}{ Níveis de levedura seca (\%) } \\
\cline { 2 - 5 } & 0 & 33 & 66 & 100 \\
\hline Fubá & 33,25 & 33,00 & 32,75 & 32,50 \\
Farelo de soja & 15,00 & 10,00 & 5,0 & 0,0 \\
Levedura seca & 0,0 & 5,0 & 10,0 & 15,0 \\
Feno de Tifton 85 & 50,0 & 50,0 & 50,0 & 50,0 \\
Ureia & 0,0 & 0,25 & 0,50 & 0,75 \\
Calcário & 1,0 & 1,0 & 1,0 & 1,0 \\
Sal mineral & 0,5 & 0,5 & 0,5 & 0,5 \\
Sal comum & 0,25 & 0,25 & 0,25 & 0,25 \\
\hline Total & 100,0 & 100,0 & 100,0 & 100,0 \\
\hline & \multicolumn{3}{c}{ Composição bromatológica } \\
\hline MS (\%) & 88,65 & 88,86 & 89,00 \\
PB (\%) & 14,82 & 14,81 & 14,81 & 14,80 \\
EM (Mcal/kg) & 2,50 & 2,50 & 2,50 & 2,50 \\
FDN (\%) & 46,23 & 45,58 & 44,93 & 44,28 \\
MM (\%) & 6,54 & 6,62 & 6,69 & 6,77 \\
CNF (\%) & 32,98 & 33,98 & 34,99 & 36,00 \\
\hline
\end{tabular}

*Fonte: Valadares Filho et al. (2010).

Terminado período experimental os animais foram submetidos a jejum de sólidos com dieta hídrica por 16 horas. Antes de serem abatidos, foram pesados, obtendo-se o peso corporal ao abate (PCA).
O abate consistiu de atordoamento, por concussão cerebral, seguido de sangria, esfola e evisceração, em abatedouro comercial. Posteriormente, foram pesados sangue, pele, cabeça, patas, fígado, aparelho reprodutor, aparelho respiratório (pulmão + traqueia), 
pulmão, coração, baço, trato gastrointestinal cheio e vazio, gordura e rins.

Após evisceração, foi estimado peso de corpo vazio (PCV), sendo definido como, peso corporal ao abate (PCA), menos, a diferença entre o conteúdo gastrintestinal, urina e suco biliar, cheio e vazio: $\mathrm{PCV}=\mathrm{PCA}-[$ (TGIC TGIV)]. Posteriormente as carcaças foram pesadas, obtendo-se o peso de carcaça quente (PCQ), possibilitandose, assim, calcular o rendimento de carcaça quente $(\mathrm{RCQ}=\mathrm{PCQ} / \mathrm{PCA} \mathrm{x}$ 100) e rendimento biológico $(\mathrm{RB}=$ $\mathrm{PCQ} / \mathrm{PCV} \times 100)$. Após pesagens, as carcaças foram acondicionadas em sacos plásticos identificadas pelos tratamentos e transportadas para câmara frigorifica a $4^{\circ} \mathrm{C}$, onde permaneceram penduradas pelos tendões calcâneos, em ganchos apropriados, por 24 horas. Ao término do período de resfriamento, foram registrados os pesos de carcaça fria (PCF), e assim calculado o rendimento de carcaça fria ou comercial $(\mathrm{RCF}=\mathrm{PCF} / \mathrm{PVA} \times 100)$.

As carcaças foram mensuradas $e$ examinadas quanto à profundidade $\mathrm{e}$ distribuição de tecidos musculares e cobertura de tecido adiposo (grau de acabamento) em relação ao tamanho do esqueleto que os sustenta, considerando-se, tanto a carcaça como um todo, como suas distintas regiões anatômicas. De acordo com Osório \& Osório (2003), atribuiu-se para grau de acabamento, escala variando de um a cinco com intervalo de meio ponto, perfazendo nove categorias.

Após a avaliação de acabamento e conformação, as carcaças foram divididas longitudinalmente, na altura da linha média, em dois antímeros. $\mathrm{Na}$ meia carcaça esquerda, foi realizado um corte transversal entre a $12^{\mathrm{a}}$ e $13^{\mathrm{a}}$ costela, expondo a secção transversal do músculo Longissimus dorsi, cuja área foi tracejada, por meio de caneta apropriada, sobre uma película plástica transparente para a determinação da área de olho-de-lombo (AOL) conforme Sen et al. (2004). Para a determinação da área de olho-de-lombo utilizou-se o software Autocad. A meia carcaça direita foi seccionada em cinco cortes comerciais: pescoço, paleta, costela, lombo e perna, os quais, após a separação, foram pesados individualmente (COLOMER-ROCHER, 1986). O pescoço refere-se as sete vértebras cervicais, onde foi separado da cabeça, por corte oblíquo, em sua extremidade inferior entre a sétima vértebra cervical e primeira torácica. A paleta refere-se à região que compreende a escápula, úmero, rádio, ulna e os carpos, é obtida por intermédio da secção da região axilar, através do corte dos tecidos que unem escápula e úmero a região torácica da carcaça. As costelas compreendem 13 vértebras torácicas, com as costelas correspondentes e esterno, e são obtidos através de dois cortes: o primeiro, entre última vértebra cervical e primeira torácica, e o segundo, entre última vértebra torácica e primeira lombar. O lombo compreende a região das vértebras lombares, obtido perpendicularmente a coluna, entre a $13^{\mathrm{a}}$ vértebra torácica primeira lombar e última lombar primeira sacral. A perna, cuja base óssea abrange a região do ilíaco (ílio), ísquio, púbis, vértebras sacrais, as duas primeiras vértebras coccígenas, fêmur, tíbia e tarso, e obtida por corte perpendicular à coluna entre a última vértebra lombar e a primeira sacra.

Também foi mensurada a espessura máxima de gordura de cobertura sobre a $12^{\mathrm{a}}$ costela, grade rule (GR) segundo Safari et al. (2001) e Kosulwat et al. (2003) e espessura de gordura subcutânea (EGS). 
Em seguida, foram efetuadas as avaliações para marmorização, coloração e textura do músculo Longissimus. As características qualitativas da carcaça, como quantidade e textura de marmoreio do músculo Longissimus dorsi e cor da carne, foram analisadas e classificadas conforme Osório \& Osório (2003). Essa metodologia atribui cinco escores para quantidade de marmoreio, que varia de um a cinco, com a seguinte classificação: inexistente, pouco, bom, muito, e excessivo. Para distribuição de marmoreio foram atribuídos três escores variando de um a três, com a seguinte classificação: desuniforme, média e uniforme. A textura de marmoreio recebeu três escores e pode ser classificada como muito grossa, medianamente grossa e levemente grosseira. A coloração do músculo Longissimus dorsi, foi classificada de um a cinco. Sendo rosa claro, rosa, vermelho claro, vermelho e vermelho escuro, respectivamente.

Para a realização dos cálculos da margem bruta, tomou-se como base, ganho de peso total no período de confinamento, preço por quilograma da carcaça na região, consumo total de matéria seca, preço por quilograma da matéria seca e despesas com vacinas e medicamentos (Adaptado de VERAS et al., 2005), segundo equação:

Margem Bruta $=$ Ganho de peso x 6,5 (CMS total x Preço Kg dieta) - DVM

Em que: $6,50=$ preço por $\mathrm{Kg}$ vivo na região $(\mathrm{R} \$)$; $\mathrm{CMS}$ total $=$ Consumo de matéria seca total; $\mathrm{DVM}=$ Despesas com vacinas e medicamentos. Para cálculo do custo da dieta, tomaram-se os seguintes preços dos ingredientes, expressos reais por quilograma: Milho: R\$ 0,80; Farelo de Soja: R\$ 0,90; Levedura seca: R\$ 0,60; Feno de Tifton-85: R\$ 0,60; ureia: R\$ 1,36; calcário: R\$ 0,20; Sal mineral: R \$ 2,50; Sal comum: $\mathrm{R} \$ 0,50$.
Os dados foram submetidos à análise de variância, incluindo a regressão polinomial no desdobramento dos tratamentos, através do software computacional SISVAR (FERREIRA, 2003), conforme modelo matemático: Yij $=\mu+\mathrm{ti}+\mathrm{bj}+\mathrm{eij}$; Yij = Valor observado da variável observada; $\mu=$ Efeito da média geral; ti $=$ Efeito de nível de inclusão de levedura; bj = Efeito de bloco; eij = Erro experimental.

\section{RESULTADOS E DISCUSSÃO}

Para as características peso corporal ao abate, consumo de matéria seca, conversão alimentar e ganho de peso diário houve efeito linear decrescente $(\mathrm{P}<0,05)$ com substituição de farelo de soja por levedura de cana-de-açúcar (Tabela 2).

Yamamoto et al. (2004) não constaram efeitos da dieta para as características supracitadas. Aguiar et al. (2007) utilizando a levedura seca em substituição ao milho e farelo de soja em dietas com ovinos observaram que a ingestão de matéria seca não foi influenciada com a inclusão de até $30 \%$ de levedura, no entanto observaram efeito negativo para digestibilidade da matéria seca, matéria orgânica e carboidratos totais e concluíram que a substituição afetou negativamente $\mathrm{o}$ consumo de energia e desempenho animal. De modo semelhante, Freitas et al. (2011) avaliaram levedura seca em substituição ao farelo de soja nas rações para cabritos e concluíram que a levedura pode ser usada como fonte proteica sem alterar a ingestão de matéria seca, porém, inclusão acima de $5,9 \%$ nas rações reduz a digestibilidade da matéria seca. 
Rev. Bras. Saúde Prod. Anim., Salvador, v.16, n.2, p.337-349 abr./jun.., 2015 http://www.rbspa.ufba.br ISSN 15199940

Tabela 2. Valores médios de peso corporal ao inicial (PCI), ao abate (PCA), consumo de matéria seca (CMS), conversão alimentar (CONV) e ganho de peso diário (GPD) de cordeiros submetidos a dietas com inclusão de levedura seca de cana-de-açúcar

\begin{tabular}{lcccccccc}
\hline \multirow{2}{*}{ Variável } & \multicolumn{5}{c}{ Níveis de inclusão } & \multirow{2}{*}{ CV (\%) } & Equação de regressão & \multirow{2}{*}{$\mathrm{R}^{2}$} \\
\cline { 2 - 5 } & 0,0 & 33,0 & 66,0 & 100,0 & & & \\
\hline PCI $(\mathrm{kg})$ & 21,70 & 21,10 & 21,55 & 21,51 & 5,93 & $\mathrm{Y}=21,468$ & - \\
PCA $(\mathrm{kg})$ & 36,74 & 34,62 & 32,51 & 30,40 & 6,05 & $\mathrm{Y}=36,741-0,211 \mathrm{x}$ & 0,90 \\
CMS $(\mathrm{kg} / \mathrm{dia})$ & 1,33 & 1,25 & 1,17 & 1,09 & 8,76 & $\mathrm{Y}=1,335-0,008 \mathrm{x}$ & 0,97 \\
CMS $(\mathrm{g} / \mathrm{PC} 0,75)$ & 87,06 & 91,01 & 87,55 & 82,32 & 7,02 & $\mathrm{Y}=0,086$ & - \\
CONV $(\mathrm{kg} / \mathrm{kg})$ & 6,96 & 7,81 & 8,67 & 9,52 & 14,38 & $\mathrm{Y}=6,961+0,085 \mathrm{x}$ & 0,93 \\
GPD $(\mathrm{kg})$ & 0,193 & 0,167 & 0,140 & 0,113 & 16,29 & $\mathrm{Y}=0,1931-0,002 \mathrm{x}$ & 0,94 \\
\hline
\end{tabular}

$\mathrm{CV}=$ coeficiente de variação; $\mathrm{R}^{2}=$ coeficiente de determinação.

Não houve diferenças significativas $(\mathrm{P}>0,05)$ para peso de sangue, aparelho reprodutivo, coração, baço e rins (Tabela 3). Com relação aos pesos de pele, cabeça, patas, fígado, aparelho respiratório, pulmão, trato digestório vazio e gordura houve efeito linear decrescente $(\mathrm{P}<0,05)$ à medida elevouse o percentual de levedura na dieta.
Para as características peso e rendimentos de carcaça quente e fria houve diferenças significativas $(\mathrm{P}<0,05)$ entre os tratamentos, com efeito linear decrescente à medida que se elevou a inclusão de levedura seca (Tabela 4). Já para rendimento biológico e perdas por resfriamento não se observou diferenças significativas $(\mathrm{P}>0,05)$.

Tabela 3. Valores médios dos componentes não carcaça de cordeiros submetidos a dietas com inclusão de levedura seca de cana-de-açúcar

\begin{tabular}{|c|c|c|c|c|c|c|c|}
\hline \multirow{2}{*}{ Variável } & \multicolumn{4}{|c|}{ Níveis de levedura seca (\%) } & \multirow{2}{*}{$\mathrm{CV}(\%)$} & \multirow{2}{*}{ Equação de regressão } & \multirow{2}{*}{$\mathrm{R}^{2}$} \\
\hline & 0,0 & 33,0 & 66,0 & 100,0 & & & \\
\hline SAN $(\mathrm{kg})^{1}$ & 1,39 & 1,191 & 1,21 & 1,17 & 19,45 & $Y=1,241$ & - \\
\hline $\operatorname{PEL}(\mathrm{kg})^{2}$ & 2,43 & 2,26 & 2,09 & 1,93 & 16,17 & $Y=2,426-0,016 x$ & 0,74 \\
\hline $\mathrm{CAB}(\mathrm{kg})^{3}$ & 2,10 & 2,00 & 1,89 & 1,79 & 8,4 & $Y=2,104-0,010 x$ & 0,92 \\
\hline $\operatorname{PAT}(\mathrm{kg})^{4}$ & 0,83 & 0,79 & 0,85 & 0,71 & 7,38 & $Y=0,831-0,0042 x$ & 0,77 \\
\hline FÍG $(\mathrm{kg})^{5}$ & 0,52 & 2,00 & 1,89 & 1,79 & 8,4 & $Y=2,104-0,0104 x$ & 0,82 \\
\hline $\operatorname{AREP}(\mathrm{kg})^{6}$ & 0,65 & 0,58 & 0,64 & 0,56 & 18,77 & $\mathrm{Y}=0,6104$ & - \\
\hline $\operatorname{ARES}(\mathrm{kg})^{7}$ & 0,74 & 0,65 & 0,56 & 0,47 & 37,19 & $Y=0,7388-0,0089 x$ & 0,75 \\
\hline $\operatorname{PUL}(\mathrm{kg})^{8}$ & 0,35 & 0,33 & 0,32 & 0,31 & 13,39 & $Y=0,0013-0,3492 x$ & 0,53 \\
\hline CORAC $(\mathrm{kg})^{9}$ & 0,14 & 0,11 & 0,12 & 0,17 & 17,95 & $\mathrm{Y}=0,121$ & - \\
\hline $\mathrm{BAC}(\mathrm{kg})^{10}$ & 0,07 & 0,07 & 0,06 & 0,06 & 37,72 & $\mathrm{Y}=0,063$ & - \\
\hline TDV $(\mathrm{kg})^{11}$ & 2,16 & 1.96 & 1,76 & 1,57 & 25,45 & $Y=2,1497-0,019 x$ & 0,62 \\
\hline GORD $(\mathrm{kg})^{12}$ & 0,43 & 0.39 & 0.36 & 0.32 & 31,22 & $Y=0,432-0,0038 x$ & 0,68 \\
\hline $\operatorname{RIN}(\mathrm{kg})^{13}$ & 0,08 & 0,09 & 0,09 & 0,10 & 21,56 & $\mathrm{Y}=0,089$ & - \\
\hline
\end{tabular}


Rev. Bras. Saúde Prod. Anim., Salvador, v.16, n.2, p.337-349 abr./jun.., 2015 http://www.rbspa.ufba.br ISSN 15199940

Tabela 4. Valores médios de peso e rendimento de carcaça quente e fria (PCQ, PCF, RCQ e RCF) perdas por resfriamento (PR) e rendimento biológico (RB) de cordeiros submetidos a dietas com inclusão de levedura seca de cana-deaçúcar

\begin{tabular}{lccccccc}
\hline \multirow{2}{*}{ Variável } & \multicolumn{5}{c}{ Níveis de inclusão } & \multirow{2}{*}{ CV } \\
& 0,0 & 33,0 & 66,0 & 100,0 & \multirow{2}{*}{ Equação de regressão } & \multirow{2}{*}{$\mathrm{R}^{2}$} \\
\hline PCQ (kg) & 16,13 & 15,05 & 13,97 & 12,72 & 8,12 & $\mathrm{Y}=16,137-0,107 \mathrm{x}$ & 0,90 \\
PCF (kg) & 15,85 & 14,81 & 13,77 & 12,72 & 8,38 & $\mathrm{Y}=15,851-0,104 \mathrm{x}$ & 0,90 \\
RCQ (\%) & 43,45 & 42,67 & 41,92 & 41,12 & 4,51 & $\mathrm{Y}=43,456-0,077 \mathrm{x}$ & 0,99 \\
RCF (\%) & 42,98 & 41,97 & 41,27 & 40,57 & 4,69 & $\mathrm{Y}=42,680-0,070 \mathrm{x}$ & 0,98 \\
PR (\%) & 1,99 & 1,34 & 1,45 & 1,46 & 57,2 & $\mathrm{Y}=1,563$ & - \\
RB (\%) & 53,36 & 53,07 & 51,42 & 52,95 & 4,82 & $\mathrm{Y}=52,706$ & - \\
\hline
\end{tabular}

$\mathrm{CV}=$ coeficiente de variação; $\mathrm{R}^{2}=$ coeficiente de determinação.

Para as características marmoreio (quantidade, distribuição e textura), cor do Longissimus dorsi, espessura de gordura subcutânea e Grade Rule não apresentaram diferença significativa $(\mathrm{P}>0,05)$ (Tabela 5). As demais características, conformidade, acabamento, gordura pélvica renal, área de olho de lombo e escore corporal reduziram-se à medida que se aumentou a inclusão de levedura seca na dieta $(\mathrm{P}<0,05)$. Observou-se valores para característica área de olho-de-lombo de
$14,47 \mathrm{~cm}^{2}$ e $11,08 \mathrm{~cm}^{2}$ para dieta controle e com substituição de 100\%, respectivamente. Resultado superior ao encontrado por Cunha et al. (2008) de $8,6 \mathrm{~cm}^{2}$ para dieta controle e $11,2 \mathrm{~cm}^{2}$ para dieta com inclusão de $40 \%$ de caroço de algodão. Urano et al. (2006) obtiveram valor semelhante de $14,8 \mathrm{~cm}^{2}$ em cordeiros Santa Inês alimentados com níveis crescentes de grão de soja, portanto semelhante a dieta controle deste estudo.

Tabela 5. Características da carcaça de cordeiros submetidos a dietas com inclusão de levedura seca de cana-de-açúcar

\begin{tabular}{|c|c|c|c|c|c|c|c|}
\hline \multirow{2}{*}{ Variável } & \multicolumn{4}{|c|}{ Níveis de levedura seca (\%) } & \multirow{2}{*}{$\mathrm{CV}(\%)$} & \multirow{2}{*}{ Equação de regressão } & \multirow{2}{*}{$\mathrm{R}^{2}$} \\
\hline & 0,0 & 33,0 & 66,0 & 100,0 & & & \\
\hline $\mathrm{CONF}^{1}$ & 2,68 & 2,48 & 2,28 & 2,08 & 17,64 & $\mathrm{Y}=2,688-0,02000 \mathrm{x}$ & 0,85 \\
\hline $\mathrm{ACA}^{2}$ & 2,66 & 2,44 & 2,38 & 2,11 & 16,51 & $Y=2,661-0,01722 x$ & 0,94 \\
\hline \multicolumn{8}{|c|}{ MARMOREIO } \\
\hline QUANT $^{3}$ & 2,33 & 2,11 & 2,44 & 2,00 & 27,39 & $\mathrm{Y}=2,22$ & - \\
\hline TEXT $^{4}$ & 3,77 & 3,88 & 3,77 & 4,11 & 9,58 & $\mathrm{Y}=3,88$ & - \\
\hline $\mathrm{CLD}^{5}$ & 1,88 & 2,00 & 1,44 & 2,11 & 40,22 & $\mathrm{Y}=1,86$ & - \\
\hline GPR $(\mathrm{kg})^{6}$ & 2,46 & 2,32 & 2,17 & 2,03 & 13,79 & $Y=2,466-0,0144 x$ & 0,78 \\
\hline EGS $(\mathrm{mm})^{6}$ & 1,55 & 1,88 & 1,22 & 1,77 & 36,21 & $\mathrm{Y}=0,15$ & - \\
\hline $\mathrm{GR}(\mathrm{mm})^{8}$ & 4,00 & 3,89 & 3,00 & 3,33 & 29,83 & $\mathrm{Y}=0,35$ & - \\
\hline $\operatorname{AOL}\left(\mathrm{cm}^{2}\right)^{9}$ & 14,47 & 13,34 & 12,21 & 11,08 & 15,27 & $Y=14,474-0,112 x$ & 0,96 \\
\hline $\mathrm{EC}^{10}$ & 3,13 & 3,00 & 2,86 & 2,72 & 10,42 & $Y=3,138-0,0137 x$ & 0,80 \\
\hline
\end{tabular}

${ }^{1}$ Conformação; ${ }^{2}$ Acabamento; ${ }^{3}$ Quantidade; ${ }^{4}$ Textura; ${ }^{5}$ Cor do Longissimus dorsi; ${ }^{6}$ Gordura pélvica renal;

${ }^{7}$ Espessura de gordura subcutânea; ${ }^{8}$ Grade Rule; ${ }^{9}$ Área de olho-de-lombo; ${ }^{10}$ Escore corporal.

$\mathrm{CV}=$ coeficiente de variação; $\mathrm{R}^{2}=$ coeficiente de determinação. 
Rev. Bras. Saúde Prod. Anim., Salvador, v.16, n.2, p.337-349 abr./jun.., 2015 http://www.rbspa.ufba.br ISSN 15199940

Observou-se que dietas com maior inclusão de levedura de cana-de-açúcar proporcionaram menores pesos de paleta, lombo, costela e perna $(\mathrm{P} \leq 0,05)$, não havendo diferenças significativas $(\mathrm{P}>0,05)$ apenas característica peso de pescoço (Tabela 6).

Com inclusão da levedura seca de canade-açúcar, reduziu-se o custo da dieta e margem bruta por cordeiro (Tabela 7).
Diferentemente dos órgãos ligados à digestão, aqueles que estão indiretamente associados(coração, rins, baço e aparelho reprodutivo, por exemplo) não são influenciados pelos níveis de energia da dieta, uma vez que os mesmos conseguem manter sua integridade por terem prioridades na utilização de nutrientes (FERREIRA et al. 2000; ALVES et al. 2003).

Tabela 6. Valores médios de pescoço (PESC), paleta (PAL), lombo (LOMB), costela (COST) e perna (PERN) da carcaça de cordeiros submetidos a dietas com inclusão de levedura seca de cana-de-açúcar

\begin{tabular}{|c|c|c|c|c|c|c|c|}
\hline \multirow{2}{*}{ Variável } & \multicolumn{4}{|c|}{ Níveis de inclusão } & \multirow{2}{*}{$\mathrm{CV}(\%)$} & \multirow{2}{*}{$\begin{array}{c}\text { Equação de } \\
\text { regressão }\end{array}$} & \multirow{2}{*}{$\mathrm{R}^{2}$} \\
\hline & 0,0 & 33,0 & 66,0 & 100,0 & & & \\
\hline PESC & 0,91 & 0,91 & 0,86 & 0,83 & 15,3 & $\mathrm{Y}=0,88$ & - \\
\hline PAL & 1,46 & 1,37 & 1,27 & 1,18 & 8,74 & $Y=1,463-0,009 x$ & 0,85 \\
\hline LOMB & 0,99 & 0,91 & 0,82 & 0,74 & 10,45 & $Y=0,994-0,008 x$ & 0,95 \\
\hline COST & 2,39 & 2,17 & 1,96 & 1,74 & 10,8 & $Y=2,391-0,021 x$ & 0,94 \\
\hline PERN & 2,33 & 2,20 & 2,06 & 1,93 & 7,78 & $Y=2,332-0,013 x$ & 0,82 \\
\hline
\end{tabular}

$\mathrm{CV}=$ coeficiente de variação; $\mathrm{R}^{2}=$ coeficiente de determinação.

Tabela 7. Margem bruta da produção de cordeiros submetidos a dietas com inclusão de levedura seca de cana-de-açúcar

\begin{tabular}{lcccc}
\hline \multirow{2}{*}{ Variável } & \multicolumn{4}{c}{ Níveis de inclusão } \\
\cline { 2 - 5 } & 0,0 & 33,0 & 66,0 & 100,0 \\
\hline Ganho de peso (kg) & 15,03 & 13,52 & 10,96 & 8,88 \\
Dieta kg/MS (R\$) & 0,71 & 0,69 & 0,68 & 0,67 \\
Preço por kg do animal (R\$) & 6,50 & 6,50 & 6,50 & 6,50 \\
Despesas com medicamentos (R\$) & 2,0 & 2,0 & 2,0 & 2,0 \\
Margem bruta/cordeiro (R\$) & 21,38 & 17,19 & 5,11 & $-0,83$ \\
\hline
\end{tabular}

Menor consumo de matéria seca, acarreta em menor disponibilidade de energia para processos metabólicos de mantença e produção, refletindo, desse modo, negativamente no crescimento corporal. De maneira geral, órgãos e tecidos envolvidos, diretamente nos processos digestivos, apresentam proporcionalidade em relação ao peso e tamanho corporal, sendo de certa forma, esperados resultados dessa magnitude
(Tabela 3), uma vez que a inclusão de levedura seca proporcionou redução no peso corporal ao abate.

Observa-se na literatura que os resultados sobre utilização da levedura de cana-de-açúcar são variáveis, devido a fatores intrínsecos (composição química, cepa utilizada e método de secagem e fermentação, por exemplo) e extrínsecos (interação com outros ingredientes da ração, espécie animal e 
estádio fisiológico, por exemplo) à levedura. Assim, devido aos fatores supracitados, é frequente a observação de resultados que recomendem sua utilização parcial (AGUIAR et al., 2007; RUFINO et al., 2013) ou até mesmo não recomendando para animais em confinamento (GOMES et al., 2011) devido a reduções no desempenho animal e características da carcaça. Recomendações de substituição parcial de fontes proteicas por levedura são sustentadas no seu potencial de redução do consumo, digestibilidade de nutrientes e interferências em parâmetros de fermentação ruminal. No tocante a reduções no consumo de matéria seca, hipóteses têm sido levantadas. A textura pulverulenta da levedura confere a ração aspecto pegajosa, dificultando sua apreensão pelo animal. Redução na digestibilidade dos nutrientes da levedura seca está associada à espessura e resistência da sua parede celular, dificultando a ação das enzimas proteolíticas com consequente diminuição do aproveitamento dos nutrientes do alimento pelo organismo (YAMADA et al. 2003).

$\mathrm{Na}$ avaliação da carcaça o fator mais importante é seu rendimento, tanto da carcaça como dos cortes primários com quantidade adequada de gordura. Inúmeros fatores afetam o rendimento de carcaça sendo eles, idade, peso corporal, genética, sexo, nutrição e alimentação, além dos ambientais. Embora os animais tenham sido abatidos com idade semelhante, a inclusão da levedura seca nas dietas, não permitiu o adequado fornecimento de nutrientes para os animais, diminuindo seu consumo, ganho de peso diário, aumentando conversão alimentar (Tabela 2), diminuindo, consequentemente, o peso corporal ao abate. Adicionalmente, devido à inclusão de a levedura seca ter proporcionado reduções no consumo de matéria seca (Tabela 2), esse fato refletiu em menor consumo de energia e deposição de gordura, bem como, características relacionadas, como conformação, acabamento, gordura subcutânea, renal e escore corporal.

A conformação pode ser considerada como fator qualitativo, levando-se em conta que animais de maior hipertrofia muscular proporcionam cortes com melhor aparência para consumidor mais exigente, ou como fator quantitativo (MULLER, 1980). Nesse último caso a afirmação baseia-se no fato de que carcaças de melhor conformação tendem a apresentar menor proporção de osso e maior de porção comestível. De maneira geral, de acordo com Colomer-Rocher (1971), admite-se que a conformação da carcaça seja um dos fatores que mais incidem sobre o valor final de comercialização da carne. Uma conformação adequada indica um desenvolvimento proporcional das distintas regiões anatômicas que integram a carcaça, e as melhores conformações são alcançadas quando as partes de maior valor comercial estão bem pronunciadas. Assim, a determinação da conformação é um critério indispensável para tipificar e classificar as carcaças (COLOMERROCHER, 1971). Segundo ColomerRocher et al. (1988), nos ovinos e bovinos, raça e gordura de cobertura ou subcutânea são os fatores que mais afetam a conformação da carcaça. Aliado as avaliações de acabamento e conformação das carcaças, a condição de escore corporal (EC), também é igualmente afetada por fatores que limitem a deposição de gordura na carcaça.

O marmoreio é uma característica importante, que está relacionado com atributos sensoriais da carne a ser consumida. Suguisawa et al. (2008) afirmaram que o marmoreio pode ser uma característica importante do ponto 
de vista comercial, aumentando a qualidade da carne ovina (sabor e suculência), como também melhorando a qualidade de vida do consumidor, por ser rico em ácido linoleico conjugado (CLA). O depósito de pequena quantidade de gordura intramuscular, de modo geral, é característica intrínseca da própria espécie ovina.

A cor da carne é determinada pela concentração total de mioglobina e pode ser afetada por alguns fatores ante mortem como a espécie, sexo e idade do animal, e por fatores post mortem, como a localização anatômica, temperatura e pH do músculo (SEIDEMAN et al., 1984).

$\mathrm{O}$ acúmulo de gordura na carcaça implica em elevada demanda ou balanço positivo de energia na dieta, devendo este nutriente ser utilizado racionalmente no sistema de produção. Excesso de gordura seja ela subcutânea e, ou, localizada no entorno de órgãos, significa desperdício no toilet, pois é retirada a faca. Por outro lado a escassez de gordura na carcaça significa aporte insuficiente de energia, mostrando uma insuficiência produtiva (PÉREZ \& CARVALHO, 2007). Brondani et al. (2006) afirmaram que a quantidade de gordura subcutânea é importante, pois, durante o resfriamento, reduz a perda por exsudação e mantém o bom aspecto visual, além de evitar ressecamento e anormalidades ligadas ao rigor mortis (encurtamento pelo frio). A característica gordura subcutânea não apresentou diferenças significativas, mesmo com outras características ligadas a esta apresentando diferenças, acabamento, por exemplo. Esse fato pode ser atribuído, a possível retirada de parte da gordura que tenha permanecido aderida a pele no momento da esfola, podendo também estar relacionada ao menor consumo de matéria seca e consequentemente menor disponibilidade de energia da dieta ingerida.

A musculosidade da carcaça diz respeito à espessura da massa muscular em relação ao tamanho do esqueleto, sendo esta característica da carcaça avaliada por diversos meios, com destaque área de olho-de-lombo (AOL). Essa porção está diretamente relacionada à quantidade de músculos da carcaça e deve ser considerada no estudo das características de carcaça como indicador do desenvolvimento muscular e do rendimento de cortes de alto valor comercial (WILLIANS, 2006). Devido redução no consumo de matéria seca, é possível, que concomitantemente tenha havido diminuições no consumo de proteína bruta, o que diminuiu a deposição de proteína para desenvolvimento muscular, acarretando em menores valores médios para a característica área de olho-de lombo.

Reduções no peso corporal ao abate (Tabela 2) acarretaram em diminuições na margem bruta por cordeiro, observando-se valores negativos quando a substituição foi integral (Tabela 7). As reduções na margem bruta por cordeiro poderiam ser ainda menores, quando no caso do pagamento por qualidade da carcaça, uma vez que, a inclusão da levedura seca diminuiu características como gordura (Tabela 3), conformação e acabamento (Tabela 5) sendo estas características ligadas à qualidade da carcaça e sensoriais da carne. As reduções na margem bruta por cordeiro poderiam ser maiores quando na utilização da levedura, se o custo para obtenção deste ingrediente fosse menor, aumentando a diferença no custo das dietas $(\mathrm{R} \$ 0,71$ e 0,67 , para ausência de levedura e substituição integral do farelo de soja, respectivamente). Gomes et al. (2011) concluíram que em dietas balanceadas, no caso de animais em confinamento, a utilização das 
Rev. Bras. Saúde Prod. Anim., Salvador, v.16, n.2, p.337-349 abr./jun.., 2015 http://www.rbspa.ufba.br ISSN 15199940

leveduras pode ser dispensável, uma vez que não apresentou efeitos benéficos sobre qualidade da carcaça, além de ser um custo adicional da dieta. A substituição do farelo de soja por levedura seca de cana-de-açúcar afeta negativamente as características da carcaça e não carcaça dos cordeiros.

\section{AGRADECIMENTOS}

A Fundação de Amparo à Pesquisa do Estado de Alagoas (FAPEAL) por parte do financiamento da pesquisa.

\section{REFERÊNCIAS}

AGUIAR, S.R.; FERREIRA, M.A.; BATISTA, A.M.V.; CARVALHO, F.F.R.; BISPO, S.V.; MONTEIRO, P.B. Desempenho de ovinos em confinamento, alimentados com níveis crescentes de levedura e ureia. Acta Scientiarum. Animal Sciences, v.29, n.4, p.411-416, 2007.

ALVES, K. S.; CARVALHO, F.F.R.; VÉRAS, A.S.C.; ANDRADE, M.A.; COSTA, R.G.; BATISTA, A.M.V.; MEDEIROS, A.N.; MAIOR JÚNIOR, R.J.S.; ANDRADE, D.K.B. Níveis de energia em dietas para ovinos Santa Inês: Desempenho. Revista Brasileira de Zootecnia, v.32, n.6, p.1927-1936, 2003.

BRONDANI, I.L.; SAMPAIO, A.A.M.; RESTLE, J.; ALVES FILHO, D.C. FREITAS, L.S.; AMARAL, G.A.; SILVEIRA, M.F.; CEZIMBRA, I.M. Composição física da carcaça e aspectos qualitativos da carne de bovinos de diferentes raças alimentados com diferentes níveis de energia. Revista Brasileira de Zootecnia, v.35, n.5, p.2034-2042, 2006.
COLOMER-ROCHER, F. Los criterios de calidad de la canal: sus implicaciones biológicas. In: CURSO INTERNACIONAL SOBRE LA PRODUCCIÓN DE OVINO DE CARNE, 1986, Zaragoza, v.2, 66p. (mimeo).

COLOMER-ROCHER, F.; MORANDFEHR, P.; KIRTON, A. H.; DELFA BELENGUER, R.; SIERRA ALFRANCA, I. Métodos normalizados para el estudio de los caracteres cuantitativos y cualitativos de las canales caprinas y ovinas. Madrid: INIA, 1988. 41p. (Cuadernos INIA, 17).

COLOMER-ROCHER, F. Valor significativo de algunas medidas de las canales procedentes del cruzamiento Landschaff por Castellana. ITEA Informacion Tecnica Economica Agraria, v.5, p.69-74, 1971.

CUNHA, M.G.G.; CARVALHO, F.F.C.; GONZAGA NETO, S.; CEZAR, M.F. Características quantitativas de carcaça de ovinos Santa Inês confinados alimentados com rações contendo diferentes níveis de caroço de algodão integral. Revista Brasileira de Zootecnia, v.37, n.6, p.1112-1120, 2008.

FERREIRA, D.F. Programa SISVAR: Sistema de análise de variância: versão 4,6 (Build 6.0). Lavras: DEX/UFLA, 2003.

FERREIRA, M.A.; VALADARES FILHO, S.C.; MUNIZ, E.B.; VERAS, A.S.C. Características das carcaças, biometria do trato gastrointestinal, tamanho dos órgãos internos e conteúdo gastrointestinal de bovinos F1 Simental $\mathrm{x}$ Nelore alimentados com dietas contendo vários níveis de concentrados. Revista Brasileira de Zootecnia, v.29, n.4, p.1174-1182, 2000. 
Rev. Bras. Saúde Prod. Anim., Salvador, v.16, n.2, p.337-349 abr./jun.., 2015 http://www.rbspa.ufba.br ISSN 15199940

FREITAS, H.S.; ALCADE, C.R.; LIMA, L.S.; ZEOLA, L.M.; COSTA, L.S.E.; LIMA, L.R. Digestibilidade total e balanço de nitrogênio em cabritos recebendo rações contendo levedura seca. Acta Scientiarum Animal Sciences, v.33, n.3, p.281-286, 2011.

GOMES, R.C.; ANTUNES, M.T.; SILVA, S.L.; LEME, P.R. Desempenho e digestibilidade de novilhos zebuínos confinados recebendo leveduras vivas e monensina. Archivos de Zootecnia, v.60, p.1077-1086, 2011.

GRANGEIRO, M.G.A.; FUENTES, M.F.F.; FREITAS, E.R.; ESPÍNDOLA, G.B.; SOUZA, F.M. Inclusão da levedura de cana-de-açúcar (Saccharomyces cerevisiae) em dietas para frangos de corte. Revista Brasileira de Zootecnia, v.30, n.3, p.766-773, 2001.

KOSULWAT, S.; GREENFIELD, H.; JAMES, J. Lipid composition of Australian retail lamb cuts with differing carcass classification characteristics.

Meat Science, v.65, p.1413-1420, 2003.

MÜLLER, L. Normas para avaliação de carcaças e concurso de carcaças de novilhos. Santa Maria, RS: UFMS, 1980. $31 \mathrm{p}$.

NATIONAL RESEARCH COUNCIL NRC. Nutrient requirements of sheep. 6.ed. Washington, D.C.: National Academy Press, 1985. 99p.

OSÓRIO, J.C.S.; OSÓRIO, M.T.M. Produção de carne ovina: técnicas de avaliação "in vivo" e na carcaça. Pelotas: UFPEL, 2003. 73p.

PÉREZ, J.R.O.; CARVALHO, P.A. Considerações sobre carcaças ovinas. In: PÉREZ, J.R.O. (Org). Ovinocultura: aspectos produtivos. Lavras: UFLA, 2007.
RUFINO, L.D.A.; PEREIRA, O.G.; RIBEIRO, K.G.; VALADARES FILHO, S.C.; CAVALI, J.; PAULINO, P.V.R. Effect of substitution of soybean meal for inactive dry yeast on diet digestibility, lamb's growth and meat quality. Small Ruminant Research, v.111, p.56-62, 2013.

SAFARI, E.; HOPKINS, D.L.; FOGARTY, N.M. Diverse lambs genotypes 4. Predicting the yield of saleable meat and high value trimmed cuts from carcass measurements. Meat Science, v.58, p.207-214, 2001.

SEIDEMAN, S.C.; CROSS, H.R.; SMITH, G.C.; DURLAND, P.R. Factors associated with fresh meat color. A review. Journal Food Quality, v.6, p.211-237, 1984.

SEN, A.R.; SANTRA, A.; KARIM, S.A. Carcass yield, composition and meat quality attributes of sheep and goat under semiarid conditions. Meat Science, v.66, p.757-763. 2004.

SUGUISAWA, L.; SOUZA, W.H.; BRADI, A.E.; WIDER, A.C.; FAUSTO, D.A.; FERREIRA, V.O. Ultrassom no melhoramento genético da qualidade da carne caprina e ovina. In: SIMPÓSIO BRASILEIRO DE MELHORAMENTO ANIMAL, 7., 2008, São Carlos, Anais... São Carlos: Sociedade Brasileira de Melhoramento Animal, 2008.

URANO, F.S.; PIRES, A.V.; SUSIN, I.; MENDES, C.Q.; RODRIGUES, G.H.; ARAÚJO, R.C.; MATTOS, W.R.S. Desempenho e característica de carcaça de cordeiros confinados alimentados com grão de soja. Pesquisa

Agropecuária Brasileira, v.41, n.1, p.1525-1530, 2006. 
Rev. Bras. Saúde Prod. Anim., Salvador, v.16, n.2, p.337-349 abr./jun.., 2015 http://www.rbspa.ufba.br

VALADARES FILHO, S.C.;

MACHADO, P.A.S.; CHIZZOTTI,

M.L.; AMARAL, H.F.; MAGALHÃES,

K.A.; ROCHA JÚNIOR, V.R.;

CAPELLE, E.R. CQBAL 3.0. Tabelas

Brasileiras de Composição de

Alimentos para Bovinos. Disponível

em: <www.ufv.br/cqbal $>$. Acesso em:

02 jul. 2011

VÉRAS, R.M.L.; FERREIRA, M.A.; VÉRAS, A.S.C.; CARVALHO, F.F.R.; CAVALCANTI, C.V.A.; SANTOS, G.R.A.; MENDONÇA, S.S.; SOARES, C.A.; SAMPAIO, C.B. Substituição do milho por farelo de palma forrageira em dietas de ovinos em crescimento.

Desempenho. Revista Brasileira de

Zootecnia, v.34, n.1, p.249-256, 2005.

WILLIANS, A.R. Ultrasound applications in beef cattle carcass research ans manegement. 2006.

Disponível em:

$<\mathrm{http}$ ://asas.org/symposia/esupp2/jas22

78.pdf $>$. Acesso em: 18 maio 2014.

YAMADA, E.A.; ALVIM, I.D.; SANTUCCI, M. C.C.; SGARBIERI, V.C. Composição centesimal e valor proteico de levedura residual de fermentação etanólica e de seus derivados. Revista de Nutrição, v.16, n.4, p.423-432, 2003.

YAMAMOTO, S.M.; MACEDO, F.A.F.; MEXIA, A.A.; ZUNDT, M.; SAKAGUTI, E.S.; ROCHA, G.B.L.; REGAÇONI, K.C.T.; MACEDO, R.M.G. Rendimentos dos cortes e nãocomponentes das carcaças de cordeiros terminados com dietas contendo diferentes fontes de óleo vegetal. Ciência Rural, v.34, p.1909-1913, 2004.

Data de recebimento: 03/06/2014

Data de aprovação: 04/05/2015 